\title{
EVALUATION OF THORACOLUMBAR INJURIES IN TRAKYA UNIVERSITY SCHOOL OF MEDICINE ACCORDING TO AOSPINE CLASSIFICATION SYSTEM
}

\author{
Gonca Aksu' ${ }^{1}$, Sercan Saran ${ }^{1}$, Mahmut Sami Oflaz ${ }^{2}$, Mert Çiftdemir ${ }^{2}$ \\ ${ }^{1}$ Trakya University School of Medicine, Edirne, TURKEY \\ ${ }^{2}$ Department of Orthopedics and Traumatology, Trakya University School of Medicine, Edirne, TURKEY
}

\begin{abstract}
Aims: This study aims to classify the thoracolumbar spinal injuries that were treated in Trakya University School of Medicine according to the recent Thoracolumbar AOSpine injury score and crosscheck the classified data with categorical modifiers such as gender, trauma type and treatment type. Methods: AOSpine Classification System was used to classify thoracolumbar spinal injuries. Classes were compared with patients' gender, age, trauma energy and treatment type. Pearson Chi-Squared test and Shapiro-Wilk test were used for statistical analysis. Results: The total number of patients was 248. One hundred fifty-two (61.3\%) were male and 96 (38.7\%) were female. One hundred and three (86.6\%) patients had high-energy trauma and 16 (13.4\%) patients had low-energy trauma in a total of 119 operated patients. Relationship between treatment type and AOSpine Classification System statistically significant. There was also a significant difference between trauma energy and AOSpine Classification System types. Conclusion: As a conclusion, gender and trauma energy were found to have a relationship and higher energy traumas were most likely to cause spinal fractures. In addition, AOSpine classification system may be one of the confounding factors regarding the choice of treatment. Keywords: Classification, spine, injury
\end{abstract}

\section{INTRODUCTION}

The most common types of injuries in the spinal cord are thoracolumbar fractures (1). The thoracolumbar segment between T11-L2 is exposed to more stress than other parts of the spine. Therefore, ninety percent of the fractures of the spine are in the thoracolumbar region (2). These injuries are usually caused by motor vehicle accidents or falling from a height. The type and intensity of these fractures depend on the age of the patient, the position of the body at the time of trauma and some other factors. Systematic classification of the thoracolumbar fractures is used for the proper diagnosis and treatment of fractures (1). Holdsworth introduced the Two-Column Concept and made a significant novelty in the thoracolumbar fracture classification. He divided the spinal cord into the anterior column (consisting of the vertebral body and disc) and the posterior column (consisting of the facet joint and posterior ligamentous complex). Holdsworth classified fractures as anterior wedge compression fracture, dislocation, rotational fracture-dislocation, extension injury, burst fracture, and shearing fracture (3).

Denis described a three-column theory in 1983 (4). According to this definition, the anterior column consists of the anterior longitudinal ligament anterior annulus fibrosus, and the anterior component of the vertebral body. The middle column consists of the posterior longitudinal ligament, the posterior vertebral wall, and the posterior annulus fibrosus. All the structures behind the posterior longitudinal ligament form the posterior column. In Denis classification, fractures are classified as compression fractures, burst fractures, seat-belt fractures, and fracture-dislocations (5).

Thoracolumbar Injury Classification and Severity (TLICS) Scale is often used by clinicians and radiologists to classify thoracolumbar fractures for developing an appropriate therapeutic strategy. For the

Address for Correspondence: Gonca Aksu, Trakya University School of Medicine, Edirne, TURKEY e-mail: gonca_aksu1998@hotmail.com ORCID: orcid.org/0000-0002-9250-012X

Received: 02.09.2019 Accepted: 05.01.2020 • DOI: 10.4274/tmsj.galenos.2020.07.01.03 Available at: tmsj.trakya.edu.tr 
classification of thoracolumbar fractures according to TLICS, 4 parameters are mainly used: morphology, neurological status, spinal cord, conus medullaris injury, and posterior ligamentous complex. Morphology is used to identify the sort of fracture. Other factors are used to diagnose the presence and level of the fracture (1). Vaccaro et al. (6) promulgated the AOSpine thoracolumbar spine injury classification system in 2013, which includes important elements of both the Magerl classification system and the TLICS.

Three main parameters are evaluated the AOSpine thoracolumbar spine injury classification: morphologic classification of the fracture, neurological status, clinical modifiers (7). Fractures are divided into 3 types, according to this classification system: Type A used for compression injuries; type B for tension band injuries and type $C$ for translation injuries. Type $A$ injuries are divided into 5 subgroups, type B injuries are divided into 3 subgroups. Neurological evaluation is classified as $\mathrm{N} 0$ for a neurologically intact patient, N1 for the transient neurological deficit, N2 for symptoms of radiculopathy, $\mathrm{N} 3$ for incomplete spinal cord injury or cauda equina injury, N4 for complete spinal cord injury and NX is used to identify patients who cannot be examined. Besides, the patient is evaluated for patient-specific circumstances: M1 is used for injuries where the posterior ligamentous complex condition is ambiguous and M2 is used to designate patient-specific comorbidity (7).

Several reliability analyses were made for the AOSpine Classification System for Thoracolumbar Injuries both worldwide by Kepler et al. (8) and regional analyses in countries like China by Cheng et al. (9) and Iran by Azimi et al. (10) throughout the years. Abedi et al. (11) published a systematic review of reliability and validity for this classification including all the valid reliability analyses published until 2019. Additionally, a revision proposal for this classification was presented by Reinhold et al. (12). Further studies are expected to make this classification accepted and frequently used worldwide.

Our study aims to classify the thoracolumbar spinal injuries that were treated in Trakya University School of Medicine according to the recent Thoracolumbar (TL) AOSIS and to crosscheck the classified data with categorical modifiers such as gender, trauma type and treatment type to see whether there is any relation present.

\section{MATERIAL AND METHODS}

This retrospective study was approved by the Scientific Research Ethics Committee of Trakya University School of Medicine (Protocol Code: TÜTF-BAEK 2019/355). In this retrospective study, the data of all patients who had admitted to Trakya University School of Medicine Orthopedics and Traumatology Department with thoracic and lumbar spine injury between January 1st, 2009 and June 1st, 2019 were collected and analyzed. Patients who rejected the treatment, patients with wrong diagnoses and patients with missing data were excluded from the study.

Gender, trauma or consultation date, trauma type if any (high or low energy)-, trauma location (thoracic or lumbar vertebrae) and treatment type (operative or non-operative) of the patients were collected from the archives of Trakya University School of Medicine. MRI, $\mathrm{X}$-Ray and CT files of the patients were used to classify the spinal injuries according to TL AOSIS (Figure 1). Only morphologic statuses were used to classify the injuries.

The data were analyzed using TURCOSA statistical software. A p-value $<0.05$ was set for the statistical significance. Shapiro-Wilk test and Kolmogorov-Smirnov test was used to test the normality of variables. Pearson Chi-Squared Test $(\chi 2)$ was conducted on categorical variables (gender, trauma type, trauma location, and treatment type). Mann Whitney $U$ test was used for non-parametric variables whereas the T-test was used for parametric variables. Numbers and percentages were used as descriptive statistics. The data were compared as gender-trauma energy, gender-treatment, and treatment-injury location. Additionally, AOSpine classification groups were compared with trauma energy, injury location and treatment procedure. Normally distributed variables were given as mean \pm standard deviation whereas non-normally distributed variables were given as median (interquartile range). 


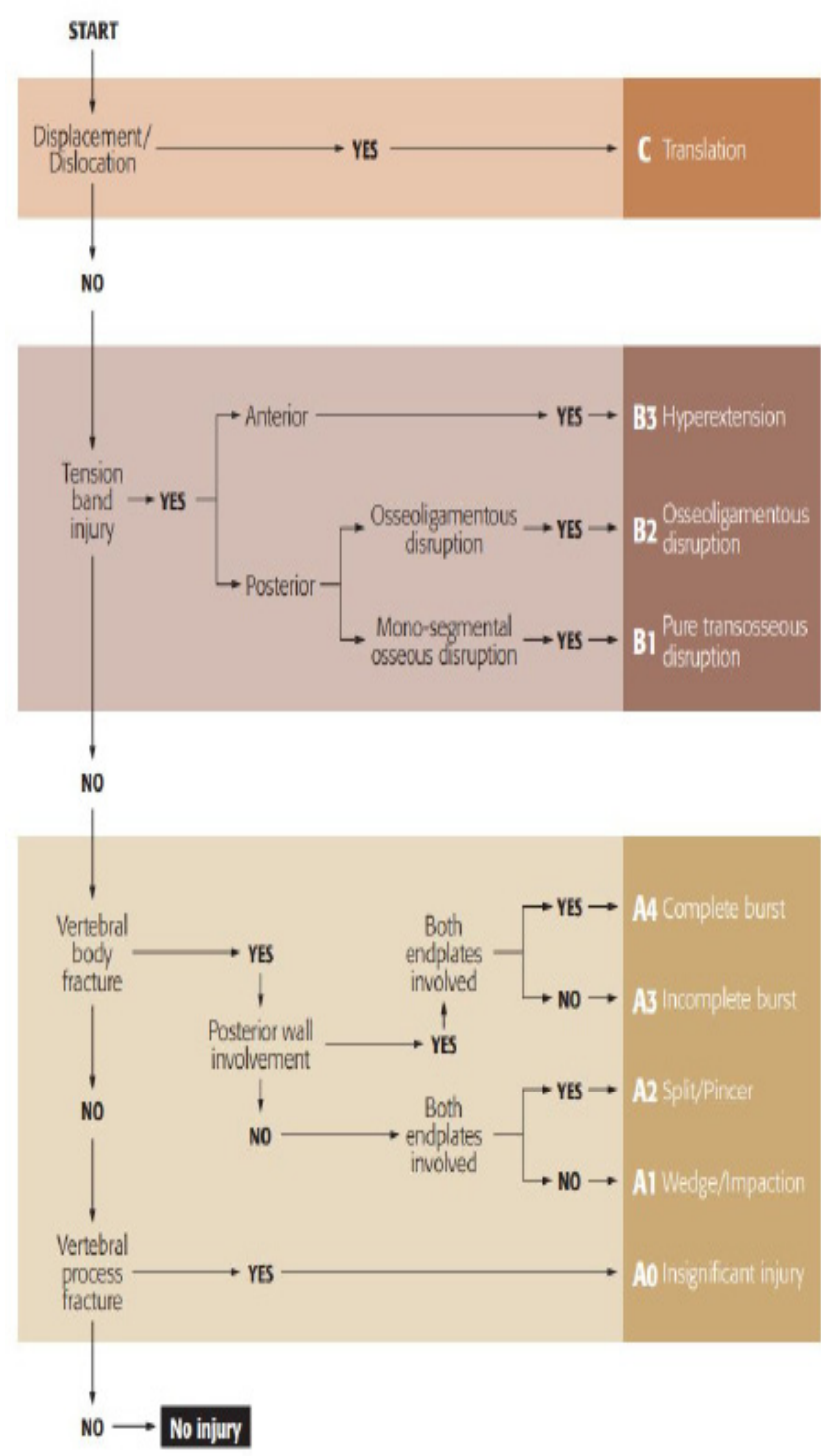

Figure 1: AOSpine thoracolumbar classification system.

\section{RESULTS}

In this retrospective study, 218 patients were included. One hundred and thirty three (61\%) of them were male and 85 (39\%) of them were female. Sixty-five $(61.32 \%)$ of the male patients were treated surgically and $68(60.71 \%)$ were treated conservatively; 41 (38.68\%) of the female patients were treated surgically and $44(39.29 \%)$ were treated conservatively. There was no statistically significant relationship between gender and treatment $(\mathrm{p}=0.927)$. When male and female patients were compared in terms of trauma energy, a statistical significance was found $(\mathrm{p}<0.001)$ (Table 1$)$.

A0 (21.8\%) and A3 (22.6\%) type fractures were frequently seen in male patients, while A3 (35.3\%) and A4 (23.5\%) type fractures were frequently seen in female patients, but this was not statistically significant $(\mathrm{p}=0.071)$ (Table 2). In addition, a statistical significance was not found between gender and the number of fractures which is shown in Table $3(\mathrm{p}=0.513)$. Table 4 shows the relationship between the injury location and trauma energy which has no statistical significance $(\mathrm{p}=0.117)$.

Two hundred eighteen patients were classified with the AOSpine Classification System according to the injury location. Fifty-two (73.24\%) of the thoracic injuries were subtype A, 18 (25.35\%) were subtype B and $1(1.41 \%)$ was subtype C. One hundred and sixteen (92.8\%) of lumbar injuries were subtype A, 8 (6.4\%) were subtype B and $1(0.8 \%)$ was subtype C. Both thoracic and lumbar injuries were all subtype $\mathrm{A}$. There was a significant relationship between fracture types and injury location $(\mathrm{p}<0.001)$.

The mean age of 218 patients was 51.28 years. The mean age of 71 patients with thoracic injury was 50.1 years, the mean age of 125 patients with lumbar injury was 51.6 years and the mean age of 22 patients with thoracal and lumbar injury was 53 years. However, there is no statistically significant relationship between age and injury site $(\mathrm{p}=0.776)$. There is a statistically significant difference between $\mathrm{AO}$ categories and terms of terms of mean age $(\mathrm{p}<0.001)$ (Table 5$)$ as well as between trauma energy and mean age. The age distribution of low energy injuries was higher than the age distribution of high energy injuries $(\mathrm{p}<0.001)$ (Table 6). The relation between AOSpine Classification System and treatment was shown in Table 7 and the relation between AOSpine Classification System and the number of fractures was shown in Table 8. Additionally, when trauma energy and AOSpine Classification groups are compared, a statistically significance was found $(\mathrm{p}=0.018)$ (Table 9). 
Table 1: The relation between gender and trauma energy.

\section{Gender}

\begin{tabular}{|c|c|c|c|c|c|c|}
\hline & & $\begin{array}{l}\text { Male } \\
\text { n (\%) }\end{array}$ & $\begin{array}{c}\text { Female } \\
\text { n (\%) }\end{array}$ & $\begin{array}{c}\text { Total } \\
n\end{array}$ & P Value & $\begin{array}{l}\text { Pearson Chi- } \\
\text { square value }\end{array}$ \\
\hline \multirow{3}{*}{$\begin{array}{c}\text { Trauma } \\
\text { Energy }\end{array}$} & High & $122(67.03 \%)$ & $60(32.97 \%)$ & 182 & \multirow{3}{*}{$<0.001$} & \multirow{3}{*}{15.6847} \\
\hline & Low & $11(31.43 \%)$ & $24(68.57 \%)$ & 35 & & \\
\hline & Total & 133 & 84 & 217 & & \\
\hline
\end{tabular}

Table 2: The relation between AOSpine classification and gender.

AOSpine Classification

\begin{tabular}{|c|c|c|c|c|c|c|c|c|c|c|c|c|c|}
\hline & & A0 & A1 & A2 & A3 & A4 & B1 & B2 & B3 & C & Total & $\begin{array}{c}\mathrm{P} \\
\text { Value }\end{array}$ & $\begin{array}{c}\text { Pearson } \\
\text { Chi- } \\
\text { square } \\
\text { value }\end{array}$ \\
\hline & $\begin{array}{l}\text { Male } \\
\text { n (\%) }\end{array}$ & $\begin{array}{c}29 \\
(21.8 \%)\end{array}$ & $\begin{array}{c}27 \\
(20.3 \%)\end{array}$ & $\begin{array}{c}8 \\
(6 \%)\end{array}$ & $\begin{array}{c}30 \\
(22.6 \%)\end{array}$ & $\begin{array}{c}21 \\
(15.8 \%)\end{array}$ & $\begin{array}{c}7 \\
(5.3 \%)\end{array}$ & $\begin{array}{c}7 \\
(5.3 \%)\end{array}$ & $\begin{array}{c}2 \\
(1.5 \%)\end{array}$ & $\begin{array}{c}2 \\
(1.5 \%)\end{array}$ & 133 & & \\
\hline Gender & $\begin{array}{l}\text { Female } \\
\mathrm{n}(\%)\end{array}$ & $\begin{array}{c}15 \\
(17.6 \%)\end{array}$ & $\begin{array}{c}5 \\
(5.9 \%)\end{array}$ & $\begin{array}{c}5 \\
(5.9 \%)\end{array}$ & $\begin{array}{c}30 \\
(35.3 \%)\end{array}$ & $\begin{array}{c}20 \\
(23.5 \%)\end{array}$ & $\begin{array}{c}3 \\
(3.5 \%)\end{array}$ & $\begin{array}{c}6 \\
(7.1 \%)\end{array}$ & 1 & $\begin{array}{c}0 \\
(1.2 \%)\end{array}$ & $\begin{array}{c}85 \\
(0 \%)\end{array}$ & 0.071 & 14.4376 \\
\hline & $\begin{array}{c}\text { Total } \\
\mathrm{n}\end{array}$ & 44 & 32 & 13 & 60 & 41 & 10 & 13 & 3 & 2 & 218 & & \\
\hline
\end{tabular}

Table 3: The relation between number of fracture and gender.

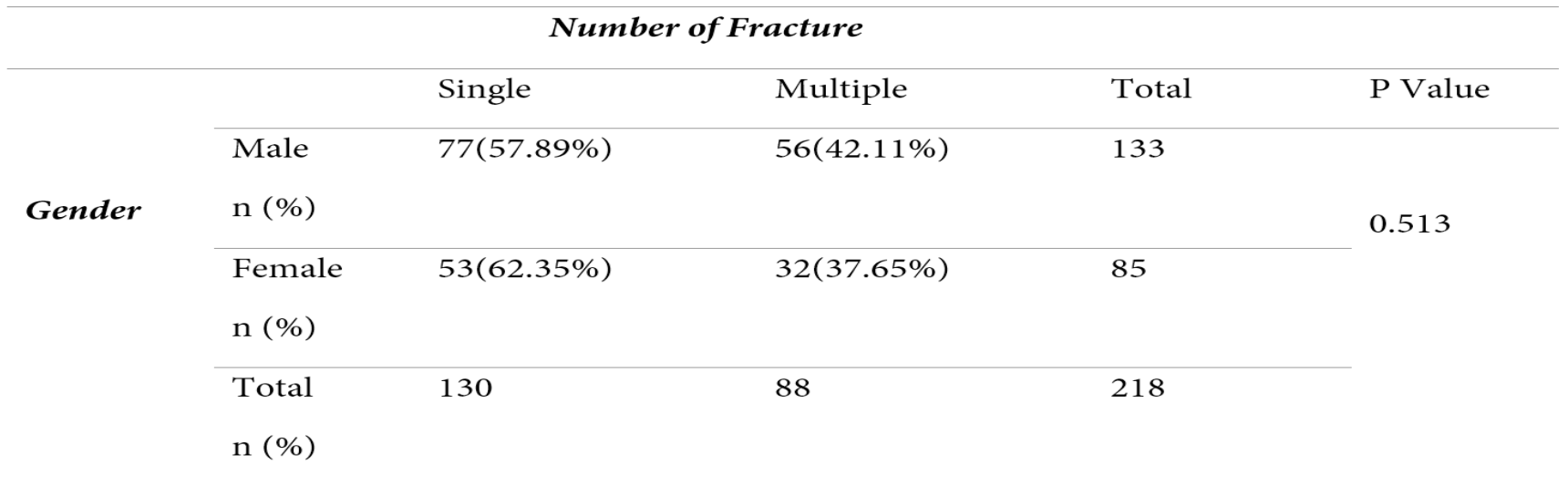


Table 4: The relation between injury location and trauma energy.

\section{Injury Location}

\begin{tabular}{|c|c|c|c|c|c|c|c|}
\hline & & $\begin{array}{c}\text { Thoracic } \\
\text { n (\%) }\end{array}$ & $\begin{array}{l}\text { Lumber } \\
\text { n (\%) }\end{array}$ & $\begin{array}{c}\text { Thoracic }+ \\
\text { Lumber } \\
\mathrm{n}(\%)\end{array}$ & $\begin{array}{l}\text { Total } \\
\text { n }\end{array}$ & P Value & $\begin{array}{l}\text { Pearson Chi- } \\
\text { square value }\end{array}$ \\
\hline \multirow{3}{*}{$\begin{array}{c}\text { Trauma } \\
\text { Energy }\end{array}$} & High & $62(34.07 \%)$ & $99(54.4 \%)$ & $21(11.54 \%)$ & 182 & \multirow{3}{*}{0.117} & \multirow{3}{*}{4.2983} \\
\hline & Low & $9(25.71 \%)$ & $25(71.43 \%)$ & $1(2.857 \%)$ & 35 & & \\
\hline & Total & 71 & 124 & 22 & 217 & & \\
\hline
\end{tabular}

Table 5: The relation between AOSpine classification system and age.

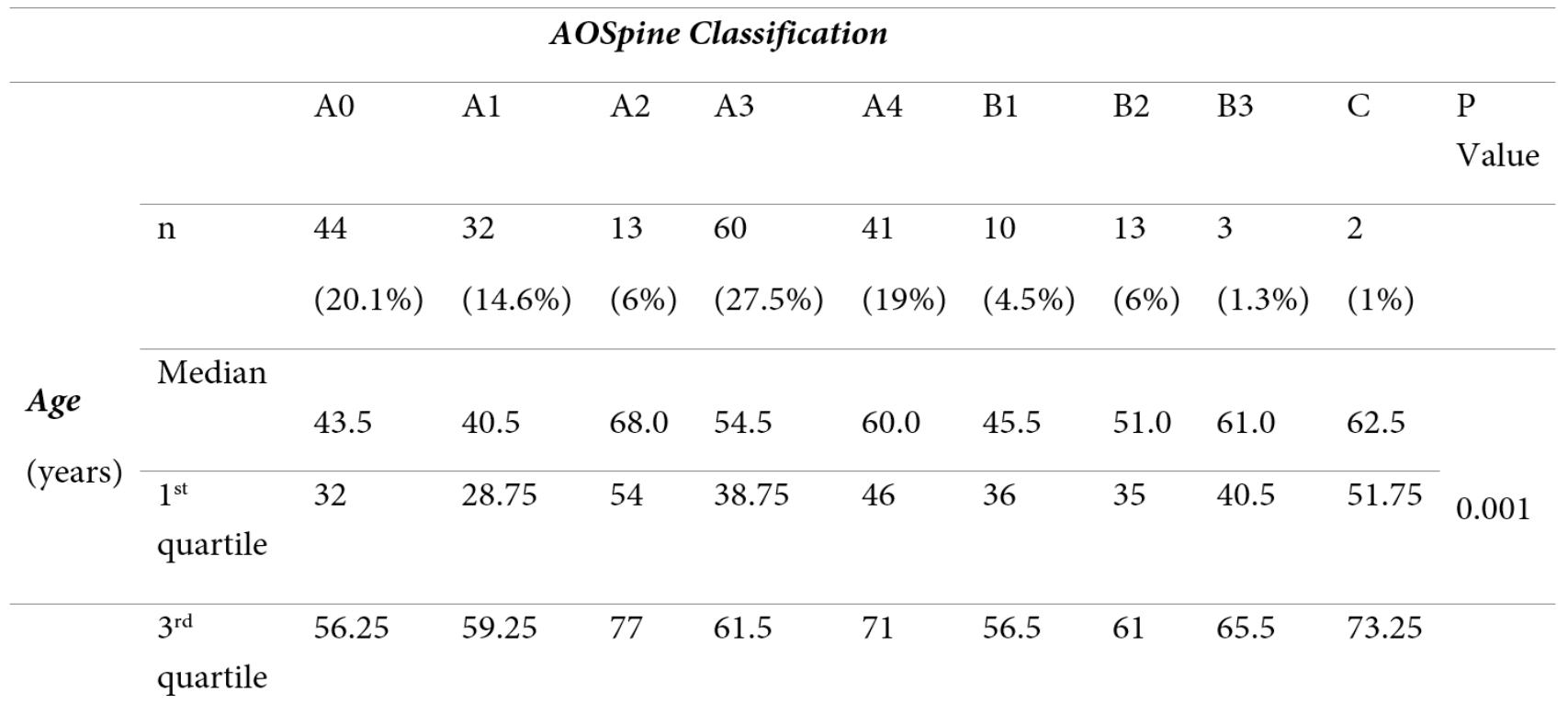

Table 6: The relation between trauma energy and age.

Age

\begin{tabular}{ccccccc} 
& & N & Median & $1^{\text {st }}$ quartile & $3^{\text {rd }}$ quartile & P Value \\
\cline { 2 - 6 } Trauma & High & 182 & 48.5 & 16 & 90 & $<0.001$ \\
\cline { 2 - 6 }$y$ & Low & 35 & 71 & 11 & 94 & \\
& Total & 217 & & &
\end{tabular}


Table 7: The relation between AOSpine Classification System and treatment.

\section{AOSpine Classification}

$\begin{array}{llllll} & \text { A } & \text { B } & \text { C } & \text { Total } & \text { P Value } \\ \text { Operative } & 81(76.4 \%) & 23(21.7 \%) & 2(1.9 \%) & 106 & \end{array}$

Treatment $\mathrm{n}(\%)$ $<0.001$

\begin{tabular}{llclc}
\hline Non-operative & $109(97.32 \%)$ & $3(2.68 \%)$ & $0(0 \%)$ & 112 \\
n $(\%)$ & & & & \\
\hline Total & 190 & 26 & 2 & 218 \\
n & & & &
\end{tabular}

Table 8: The relation between AOSpine classification system and number of fracture.

AOSpine Classification

\begin{tabular}{|c|c|c|c|c|c|c|c|c|c|c|c|}
\hline & & A0 & A1 & $\mathrm{A} 2$ & A3 & A4 & B1 & B2 & B3 & $\mathrm{C}$ & $\begin{array}{c}\mathrm{P} \\
\text { Value }\end{array}$ \\
\hline Number & Single & $\begin{array}{c}7 \\
(5.38 \%)\end{array}$ & $\begin{array}{c}16 \\
(12.31 \%)\end{array}$ & $\begin{array}{c}8 \\
(6.15 \%)\end{array}$ & $\begin{array}{c}43 \\
(33.08 \%)\end{array}$ & $\begin{array}{c}37 \\
(28.46 \%)\end{array}$ & $\begin{array}{c}7 \\
(5.38 \%)\end{array}$ & $\begin{array}{c}10 \\
(7.69 \%)\end{array}$ & $\begin{array}{c}1 \\
(0.77 \%)\end{array}$ & $\begin{array}{c}1 \\
(0.77 \%)\end{array}$ & \multirow{2}{*}{$<0.001$} \\
\hline & Multiple & $\begin{array}{c}37 \\
(42.05 \%)\end{array}$ & $\begin{array}{c}16 \\
(18.18 \%)\end{array}$ & $\begin{array}{c}5 \\
(5.68 \%)\end{array}$ & $\begin{array}{c}17 \\
(19.32 \%)\end{array}$ & $\begin{array}{c}4 \\
(4.55 \%)\end{array}$ & $\begin{array}{c}3 \\
(3.41 \%)\end{array}$ & $\begin{array}{c}3 \\
(3.41 \%)\end{array}$ & $\begin{array}{c}2 \\
(2.27 \%)\end{array}$ & $\begin{array}{c}1 \\
(1.14 \%)\end{array}$ & \\
\hline & Total & 44 & 32 & 13 & 60 & 41 & 10 & 13 & 3 & 2 & \\
\hline
\end{tabular}

Table 9: The relation between AOSpine classification system and trauma energy.

AOSpine Classification

\begin{tabular}{|c|c|c|c|c|c|c|c|c|c|c|c|}
\hline & & A0 & $\mathrm{Al}$ & A2 & $\mathrm{A} 3$ & A4 & B1 & B2 & B3 & $\mathrm{C}$ & $\begin{array}{c}\mathrm{P} \\
\text { Value }\end{array}$ \\
\hline \multirow{5}{*}{$\begin{array}{c}\text { Trauma } \\
\text { Energy }\end{array}$} & & 2 & 5 & 6 & 13 & 8 & 0 & 1 & 0 & 0 & \multirow{5}{*}{0.018} \\
\hline & & $(5.71 \%)$ & $(14.29 \%)$ & $(17.14 \%)$ & $(37.14 \%)$ & $(22.86 \%)$ & $(0 \%)$ & $(2.86 \%)$ & $(0 \%)$ & $(0 \%)$ & \\
\hline & \multirow{2}{*}{ High } & 42 & 27 & 7 & 46 & 33 & 10 & 12 & 3 & 2 & \\
\hline & & $(23.08 \%)$ & $(14.84 \%)$ & $(3.85 \%)$ & $(25.27 \%)$ & $(18.13 \%)$ & $(5.49 \%)$ & $(6.59 \%)$ & $(1.65 \%)$ & $(1.1 \%)$ & \\
\hline & Total & 44 & 32 & 13 & 59 & 41 & 10 & 13 & 3 & 2 & \\
\hline
\end{tabular}




\section{DISCUSSION}

In this study, the thoracolumbar spine injuries treated in Trakya University School of Medicine were classified according to the most recent thoracolumbar injury classification system TL AOSIS. The frequency of the injury types were analyzed and the classified injuries were crosschecked with the other variables (treatment procedure, gender, age, trauma type, injury location). Only morphological statuses of the injuries were included in the classification as a result of lacking information about neurological statuses and clinical modifiers of the patients.

Among the 217 patients with thoracolumbar injuries, $61.3 \%$ were male and $38.7 \%$ were female; the male-to-female ratio was 1.58 to 1 . This ratio stays approximately the same when the non-operated and operated patients were categorized according to their genders. However, this finding was not statistically significant. The male predominance was similiar with the literature (13-15). The difference between the treatment methods and gender was also statistically insignificant as well as the study of Dodwad SN et al. (13). In the male population, $8.2 \%$ of injuries were caused by low energy trauma. However, in the female population, the percentage of low energy trauma was increased to $28.6 \%$ of which $79.1 \%$ being over the age of 55 . These findings were similar to the review by Schousboe JT et al. (14) which may be attributed to the fact that osteoporosis being more prevalent in women (16). Patients who were over the age of 55 consist $80 \%$ of the 35 patients who were injured as a result of low energy trauma even though the number of patients may not be sufficient to come up with a strong hypothesis, this data might suggest a higher tendency of bone fragility in older women than men.

Most of the thoracolumbar injuries in this study were located in the lumbar region of the spine (57.3\%). In another research by Sidon et al. (15), lumbar spinal injuries were found to be the majority in terms of overall spinal fractures supporting our findings. Sidon et al. (15) also state that lumbar fractures were found to be more frequent in women than men and this statement was also supported by another research by Hoy et al. (17). Similar to these researches, lumbar spinal injuries were found to be slightly higher in women (62.6\%) than men (60.4\%). However the data was insignificant in this study and the $2 \%$ difference between genders was not high enough to strongly support the mentioned studies. When classification of subtypes for overall thoracolumbar injuries were compared, A-type injuries were observed to be the most common and $\mathrm{C}$ type were the least common fracture type corresponding to the findings of the research by Rajasekaran et al. (18). On the contrary, the most common fracture subtype was A3 in our study which was different than the research by Rajasekaran et al. (18) in which the most common fracture subtype was B2. This could show that a generalization about subtypes' frequency cannot be made although $\mathrm{A}$ and $\mathrm{C}$ type injuries might be accepted as the most and least common fracture types respectively, considering the mechanism and the severity of the fractures and the statistics of the research by Rajasekaran et al. (18). Further studies are needed in this matter. According to the analyzed data, A-type fractures were more common in the thoracic spine (73.24\%). This might lead us to assume a relationship between the localization and the type of fracture.

The relationship between the trauma energy and the treatment was not significant. Operatively and non-operatively treated patients were distributed almost equally in high-energy-related trauma patients different from in low-energy-related trauma patients as most of the group $(62.9 \%)$ was composed of non-operatively treated patients. The findings were similar for patients older than 55 . However, there was a statistical significance found between TL AOSIS subtypes regarding the trauma energy. This significance was noticeable in the A2 subgroup and further as the low-energy-related trauma percentage decreases while the subgroups proceed towards Type $\mathrm{C}$ fractures with one exception on the B2 subgroup which may be the cause of the insufficient number of patients for each subgroup in Type $B$ fractures. Another remarkable finding in this retrospective study was the relationship between the AOSpine TLICS subgroups and the treatment. There was a statistically significant relationship between the fracture types and the choice of treatment $(p<0.001)$. The data showed that as the fracture types progressed from $\mathrm{A}$ subgroups towards $\mathrm{C}$ group, the percentage of surgical intervention increased visibly. It is believed that the inconsistency in Type B subgroups was caused by the insufficient number of patients as it is stated previously. The relationships between AOSpine TLICS subgroups and the trauma energy and treatment correlate with the Thoracolumbar AOSpine Injury Score developed by Kepler et al. (19) and a research made to help with the treatment of spinal injuries depending on the subtypes which suggest as the subgroups progress the severity score of the injury and chance of surgical intervention increases (7).

The mean age of the patients was crosschecked with other variables and there was an interesting statistical significance found between the AOSpine TLICS groups 
$(\mathrm{p}<0.001)$. Type $\mathrm{C}$ injuries were excluded in this matter because of the insufficient number of patients. This statistical significance was caused by the mean age differences between A2-A0, A4-A0, A2-A1, A4-A1. Type $B$ groups that had not enough number of examples did not cause any statistical significance. It could be hypothesized that if the number of injuries evaluated increases a connection could be found among the subgroups and mean age of the related patients. Another and relatively important statistical significance observed was between the trauma energy and the mean age of the related patients. While the mean age of the patients who experienced low-energy-related trauma was 71 years, the mean age concerning the high-energy-related trauma was 48.5 years which would show a remarkable difference between high and low-energy-related trauma. Similarly, when the patients older and younger than 55 years were crosschecked with trauma energy; $80 \%$ of the low-energy-related trauma was observed in the patient group older than 55 years showing us an important and statistically significant result. Therefore, the increase in severity causes an increase in the surgical intervention need and a tendency towards being the result of high-energy-related traumas. This is probably because of the changes in BMD and general bone structure for both males and females which was mentioned in numerous studies in the literature $(15,20,21)$.

There were some significant limitations in the study, the main one being the low number of patients for some of the observation groups like $\mathrm{C}$ Group injuries and lack of information about the other modifiers such as neurologic status and patient-specific modifiers in the patients' archive files. Nonetheless, we used most of the available information to minimize the limitations. To see a more accurate distribution of the subtypes and other modifiers and achieve concrete results, larger sample groups were needed.

As a conclusion, gender and trauma energy were found to have a relationship and higher energy traumas were most likely to cause spinal fractures. In addition, the results of our study showed that the AOSpine classification system may be one of the confounding factors regarding the choice of treatment such as conservative or operative. Similarly, age was an effective factor for the changes in general bone structure making older patients vulnerable to serious injuries even as a result of low-energy-related trauma. Further studies are needed to specify the frequency of TL AOSIS subtypes and clarify the effects of fracture types, neurological status and patient-specific modifiers on the treatment.
Ethics Committee Approval: This retrospective study was approved by the Scientific Research Ethics Committee of Trakya University School of Medicine (TÜTF-BAEK 2019/355)

Informed Consent: Written informed consent was obtained from the participants of this study.

Conflict of Interest: The authors declared no conflict of interest.

Author contributions: Concept: GA, SS, MSO, MÇ. Supervision: GA, SS, MSO, MÇ. Resources: GA, SS, MSO, MÇ. Materials: GA, SS, MSO, MÇ. Data collection and/or processing: GA, SS, MSO, MÇ. Analysis and/or Interpretation: GA, SS, MSO, MÇ. Literature Search: GA, SS, MSO, MÇ. Writing Manuscript: GA, SS, MSO, MÇ. Critical Review: GA, SS, MSO, MÇ.

Financial disclosure: The authors declared that this study received no financial support.

\section{REFERENCES}

1. Mohamadi A, Googanian A, Ahmadi A et al. Comparison of surgical or nonsurgical treatment outcomes in patients with thoracolumbar fracture with Score 4 of TLICS: a randomized, single-blind, and single-central clinical trial. Medicine (Baltimore) 2018;97(6):e9842.

2. Kim BG, Dan JM, Shin DE. Treatment of thoracolumbar facture. Asian Spine Journal 2015;9(1):133-46.

3. Azam MQ, Sadat-Ali M. The concept of evolution of thoracolumbar fracture classifications helps in surgical decisions. Asian Spine J 2015;9(6):984-94.

4. Denis F. The three column spine and its significance in the classification of acute thoracolumbar spinal injuries. Spine 1983;8(8):81731.

5. Gomleksiz C. Thoracolumbar fractures: a review of classifications and surgical methods. Journal of Spine 2015;04:250.

6. Vaccaro AR, Oner C, Kepler CK et al. AOSpine thoracolumbar spine injury classification system: fracture description, neurological status, and key modifiers. Spine 2013;38(23):2028-37.

7. Vaccaro AR, Schroeder GD, Kepler CK et al. The surgical algorit$\mathrm{hm}$ for the AOSpine thoracolumbar spine injury classification system. Eur Spine J 2016;25(4):1087-94.

8. Kepler CK, Vaccaro AR, Koerner JD et al. Reliability analysis of the AOSpine thoracolumbar spine injury classification system by a worldwide group of naïve spinal surgeons. European Spine Journal 2015;25(4):1082-86.

9. Cheng J, Liu P, Sun D et al. Reliability and reproducibility analysis of the AOSpine thoracolumbar spine injury classification system by Chinese spinal surgeons. European Spine Journal 2016;26(5):147782.

10. Azimi P, Mohammadi HR, Azhari S et al. The AOSpine thoracolumbar spine injury classification system: a reliability and agreement study. Asian J Neurosurg 2015;10:282-5.

11. Abedi A, Mokkink LB, Zadegan SA et al. Reliability and validity of the AOSpine thoracolumbar injury classification system: a systematic review. Global Spine J 2019;9(2):231-42. 
12. Reinhold M, Audigé L, Schnake KJ et al. AO spine injury classification system: a revision proposal for the thoracic and lumbar spine. Eur Spine J. 2013;22(10):2184-201.

13. Dodwad SN, Dodwad SJ, Wisneski R et al. Retrospective analysis of thoracolumbar junction injuries using the thoracolumbar injury severity and classification score, American spinal injury association class, injury severity score, age, sex and length of hospitalization. Journal of Spinal Disorders and Techniques 2015;28(7):410-6.

14. Schousboe JT. Epidemiology of vertebral fractures. Journal of Clinical Densitometry 2016;19(1):8-22.

15. Sidon E, Stein M, Ramalingam G et al. Gender differences in spinal injuries: causes and location of injury. Journal of Women's Health 2018;27(7):946-51.

16. Hernlund E, Svedbom A, Ivergård M et al. Osteoporosis in the European Union: medical management, epidemiology and economic burden. A report prepared in collaboration with the International Osteoporosis Foundation (IOF) and the European Federation of Pharmaceutical Industry Associations (EFPIA). Archives of Osteoporosis 2013;8:136.

17. Hoy D, Brooks P, Blyth F et al. The epidemiology of low back pain. Best Pract Res Clin Rheumatol 2010;24(6):769-81.

18. Rajasekaran S, Vaccaro AR, Kanna RM et al. The value of CT and MRI in the classification and surgical decision-making among spine surgeons in thoracolumbar spinal injuries. Eur Spine J 2017;26(5):1463-9.

19. Kepler CK, Vaccaro AR, Schroeder GD et al. The thoracolumbar AOSpine injury score. Global Spine Journal 2016;6(4):329-34.

20. Jordan KM, Cooper C. Epidemiology of osteoporosis. Best Practice \& Research Clinical Rheumatology 2002;16(5):795-806.

21. Melton III LJ, Thamer M, Ray NF et al. Fractures attributable to osteoporosis: report from the National Osteoporosis Foundation. Journal of Bone and Mineral Research 1997;12(1):16-23. 